JURNAL PENDIDIKAN USIA DINI

DOI: https://doi.org/10.21009/JPUD.121
DOI: https://doi.org/10.21009/JPUD.121 07

\title{
MODEL PERMAINAN ESTAFET BAIT LAGU UNTUK MENINGKATKAN KEMAMPUAN PEMUSATAN PERHATIAN PADA ANAK
}

\author{
ISMANIAR \\ Jurusan PLS FIP UNP, Indonesia \\ Email: ismaniar.js.pls@fip.unp.ac.ad
}

\begin{abstract}
ABSTRAK
The motivated this research is by the still low development of attention concentration ability in early childhood.The purpose of this study is to develop a model of selective attention playing for children in group B kindergarten Al Ittihaad Bekasi. The study was a Research and Development $(R \& D)$, developed by Borg \& Gal. Model development through three stages is (1) needs analysis process, (2) product development process, and (3) tesing process.After the experimental process in the research as well as input from teachers using this model,has been very encouraging and axpert advices add the finishing touch.The model effectiveness tes showed a significant increase in the process of assisting children with low selective attention ability. Estafet Bait Lagu Model is consist of guide book, medias, and assesment.
\end{abstract}

Keyword: The ability of selective attention, development, play model, estafet bait lagu

Latar belakang penelitian ini adalah masih rendahnya perkembangan kemampuan pemusatan perhatian pada anak usia dini. Penelitian bertujuan untuk mengembangkan model permainan pemusatan perhatian pada anak-anak di kelompok B TK Al Ittihaad Bekasi. Penelitian ini merupakan Penelitian dan Pengembangan $(R \& D)$, menggunakan desain yang dikembangkan oleh Borg \& Gall. Pengembangan model melalui tiga tahapan yaitu (1)proses analisis kebutuhan,(2) proses pengembangan produk dan (3) proses pengujian. Setelah dilakukan beberapa kali uji coba, masukan dari guru pengguna model ini sudah sangat menggembirakan dan sentuhan terakhir dengan menambahkan pendapat dan masukan pakar. Pengujian efektivitas model memperlihatkan terjadi peningkatan yang cukup signifikan dalam hal proses membantu anak-anak yang memiliki kemampuan pemusatan perhatian yang rendah. Model Estafet Bait Lagu terdiri dari buku panduan, media, dan penilaian.

Kata kunci; kemampuan pemusatan perhatian, pengembangan, model permainan, estafet bait lagu 


\section{PENDAHULUAN}

Studi pendahuluan di beberapa TK di wilayah Bekasi dan hasil wawancara langsung dengan guru serta kepala sekolah TK, menunjukkan banyak anak yang mengalami masalah dalam kemampuan pemusatan perhatian. Sementara guru belum mempunyai cara penanganan khusus dalam menghadapi masalah tersebut. Hal ini menyebabkan kondisi kelas sering gaduh dan banyak pekerjaan anak yang tidak selesai pada waktunya. Padahal kegiatan-kegiatan yang diberikan guru kepada anak sudah mempertimbangkan waktu dan tugas perkembangan anak usia TK.

Permasalahan kemampuan pemusatan perhatian anak di antaranya ditemui di TKQ Al-Ittihad Kota Bekasi. Dari empat aspek kemampuan pemusatan perhatian yang peneliti amati yaitu mengontrol perilaku, memfokuskan perhatian, menunjukkan kesungguhan dan mempertahankan perhatian, hasil observasi pada 26 orang anak diperoleh data; hanya $27 \%$ dari keseluruhan anak yang memiliki kemampuan pemusatan perhatian dalam kriteria terlihat konsisten, 42 $\%$ dari keseluruhan anak memiliki kemampuan pemusatan perhatian dengan kriteria Sudah terlihat tetapi tidak konsisten dan $31 \%$ dari keseluruhan anak memiliki kemampuan pemusatan perhatian dengan kriteria tidak terlihat. Berdasarkan data tersebut maka kemampuan pemusatan perhatian anak kelompok B3 TKQ Al-Ittihad Kota Bekasi masih dalam kategori rendah.

Perhatian merupakan pre requisite/persyaratan dalam melakukan tugas-tugas belajar. Oleh sebab itu, salah satu yang perlu dituntaskan anak dalam masa perkembangannya adalah kemampuan dalam menentukan pilihan terhadap apa yang perlu diperhatikan-nya. Kemampuan ini membantu anak dalam memproses stimulasi atau rangsangan yang ditangkap oleh panca indra dengan cermat. Ketidakmampuan untuk menentukan pilihan dalam pemusatan perhatian, akan menyebab-kan anak tidak dapat memproses stimulasi dengan cermat dan tidak fokus/ memindahkan 
Model Permainan Estafet Bait Lagu... Ismaniar

perhatiannya sebelum ia dapat mengambil manfaat dari stimulus yang diperhatikannya.

$$
\text { Hasil penelitian yang }
$$
dilakukan Gearheart (dalam Jamaris, 2009), anak pra sekolah memiliki rentang pemusatan perhatian antara 10 menit sampai dengan 20 menit. Model permainan yang tepat menjadi salah satu penentu keberhasilan dalam kegiatan stimulasi perkembangan anak usia dini. Permainan sangat penting digunakan dalam kegiatan pengembangan anak usia dini, karena stimulasi yang dilakukan akan mudah diterima oleh anak melalui kegiatan bermain, termasuk dalam stimulasi peningkatan kemampuan pemusatan perhatian. Spencer (dalam Musfiroh, 2008) mengatakan bermain sangat penting bagi perkembangan anak. Anak-anak harus mengalami masa bermain agar mereka dapat mencapai perkembangan yang optimal. Tedjasaputra (2001) mengatakan banyak sekali manfaat yang dapat mereka peroleh melalui kegiatan bermain aktif. Di antaranya bermain dapat mengembangkan kemampuan anak untuk berdaya cipta (kreatif), bermain melatih keterampilan motorik halus, bermain melatih kosentrasi/ pemusatan perhatian, serta bermain dapat melatih ketekunan dan daya tahan anak. Lebih lanjut Tedjasaputra (2001) mengatakan aktivitas musik bisa digolongkan ke dalam jenis bermain aktif, hal ini terjadi bila anak melakukan kegiatan musik misalnya dalam bentuk aktivitas bernyanyi, memainkan alat musik tertentu atau melakukan gerakan-gerakan atau tarian yang diiringi musik. Lebih lanjut faktanya bernyanyi merupakan kegiatan yang paling banyak dilakukan orang karena tidak menuntut keahlian memainkan alat musik tertentu.

\section{KAJIAN TEORITIK}

Mengacu beberapa teori tentang pemusatan perhatian yang dikemukakan oleh Magill, Santrock, Lehman, Alston, Ross, Shcunk dan Berk, dapat disimpulkan kemampuan pemusatan perhatian adalah kapasitas yang dimiliki setiap orang baik mental maupun fisik, yang digunakan dalam memilih/ menentukan suatu informasi atau 
kegiatan yang akan dilakukan, tanpa teralihkan oleh sekian banyak rangsangan baik internal maupun eksternal pada jangka waktu tertentu. Lebih jauh, Carolyn Olivier dan Rosemary Bowler (dalam Berk, 2006) mengemukakan bahwa perhatian terpusat mencakup berbagai fungsi yang mengontrol dan mengatur apa yang kita pikirkan dan lakukan. Berikut ini adalah beberapa yang paling penting dari fungsifungsi perhatian terpusat; menentukan pilihan apa yang penting dan mengabaikan atau menyaring apa yang tidak penting untuk tugas yang dilakukan, (2) mengalokasikan energi mental untuk tugas tertentu dan mengalihkan fokus diantara mereka, (3) melihat kembali bahwa apa yang akan dilakukan, memantau atau memper hatikan apa yang dilakukan seperti yang akan dilakukan dan memeriksa apa yang telah dilakukan, (4) mengatur fisik dan energi mental, serta pikiran, perasaan, dan keinginan sementara melakukan tugas.

Permainan estafet bait lagu merupakan suatu bentuk inovasi dalam kegiatan bermain musik khususnya bernyanyi, dimana dalam pelaksanaan kegiatan permainan anak terlibat langsung baik secara kelompok maupun individual dalam menyanyi atau bergerak sesuai aturan main yang sudah ditetapkan. Aturan-aturan yang dibuat dalam permainan mengharuskan anak untuk selalu menjaga perhatiannya agar dapat bermain dengan baik, dan hal ini jika dilakukan secara berulang akan membuat anak terlatih untuk memusatkan perhatiannya. Stellaco dan McCarthy juga menguatkan pendapat di atas, dia mengatakan: Music is an important vehicle for cognitive, social and physical development in very young children (Stellaccio \& McCarthy, 1999). Penggunaan musik dalam berbagai aktifitas pembelajaran dapat membantu proses stimulasi. Terkait dengan penggunaan musik dalam stimulasi perkembangan anak, Sousa (2012) mengatakan bahwa musik akan memberikan efek yang kuat pada bagian otak karena dapat menstimulasi ranah intelektual dan emosional manusia. Musik menstimulasi gerakan dan mengembangkan kemampuan koor 
Model Permainan Estafet Bait Lagu... Ismaniar

dinasi fisik serta pengendaliannya. orang anak dari TK Alittihad Bekasi, Gerakan adalah katalis kunci untuk dan sampel uji luas sebanyak 42 perkembangan koordinasi kinestetik, sedangkan musik adalah salah satu stimulan utama untuk orang anak dari dua sekolah yaitu TKIT Iskandar Muda dan TK Al Izzah.

mengendalikan gerakan. Oleh karenanya, musik dapat membantu pengendalian konsentrasi dan memungkinkan anak berkonsentrasi pada aktivitas belajar untuk waktu yang lebih lama.

\section{METODOLOGI PENELITIAN}

Prosedur yang digunakan dalam penelitian ini adalah research and development, model Borg and Gall. Langkah-langkah penelitian meliputi; 1) tahap studi pendahuluan dan analisis kebutuhan, 2) analisis instruksional, 3) identifikasi perilaku dan karakteristik awal, 4) perancangan, 5) pengembangan draft model 1,6) uji coba terbatas; draft model pertama, 7) revisi; uji pakar dan teman sejawat, 8) uji coba luas; draft model kedua, 9) revisi akhir, 10) finalisasi model/pelaporan (Gall, Borg, \& Gall, 2003).

Sampel penelitian diambil dengan teknik Purposive Sampling. Sampel uji terbatas sebanyak 25

Pengumpulan data dilakukan dengan beberapa teknik meliputi; observasi, wawancara, angket dan tes sesuai data yang dibutuhkan. Untuk mengukur peningkatan kemampuan pemusatan perhatian anak, peneliti mengembangkan instrument sendiri, dan melakukan uji pakar untuk validitas instrumen.Sementara analisis data penelitian dilakukan menggunakan pendekatan kualitatif dan kuantitatif yaitu sesuai dengan jenis datanya ada.

\section{HASIL DAN PEMBAHASAN}

Hasil penelitian ini: 1) Dari studi pendahuluan ke beberapa TK di wilayah Bekasi, peneliti menemukan kenyataan bahwa "Belum ada metode/cara khusus yang dikuasai guru dalam menangani masalah pemusatan perhatian pada anak. Penanganan yang dilakukan selama ini hanya berupa penanganan insidental atau situasional". Jadi Kesimpulannya Model Permainan 
JURNAL PENDIDIKAN USIA DINI

Volume 12 Edisi 1, April 2018

Estafet Bait Lagu merupakan model inovatif untuk meningkatkan kemampuan pemusatan perhatian anak di wilayah Bekasi. 2) Proses peran cangan model permainan estafet bait lagu ini sudah dilakukan melalui kajian teoritis yang mendalam serta mengalami beberapa proses uji cobas di lapangan. Karakteristik serta gaya belajar anak yang berbeda-beda menjadi pertimbangan dasar pengembangan model permainan ini serta sudah dilakukan proses validasi ahli. Produk Model Permainan Estafet Bait Lagu disertai adanya buku panduan, Media Permainan dan instrumen perkembangan kemam puan pemusatan perhatian anak. Rekomendasi teman sejawat dan validasi ahli menunjukkan bahwa produk model permainan estafet bait lagu praktis dan efektif digunakan. Model permainan estafet bait lagu untuk meningkatkan kemampuan pemusatan perhatian anak yang dihasilkan sebagi berikut;
E-ISSN:2503-0566

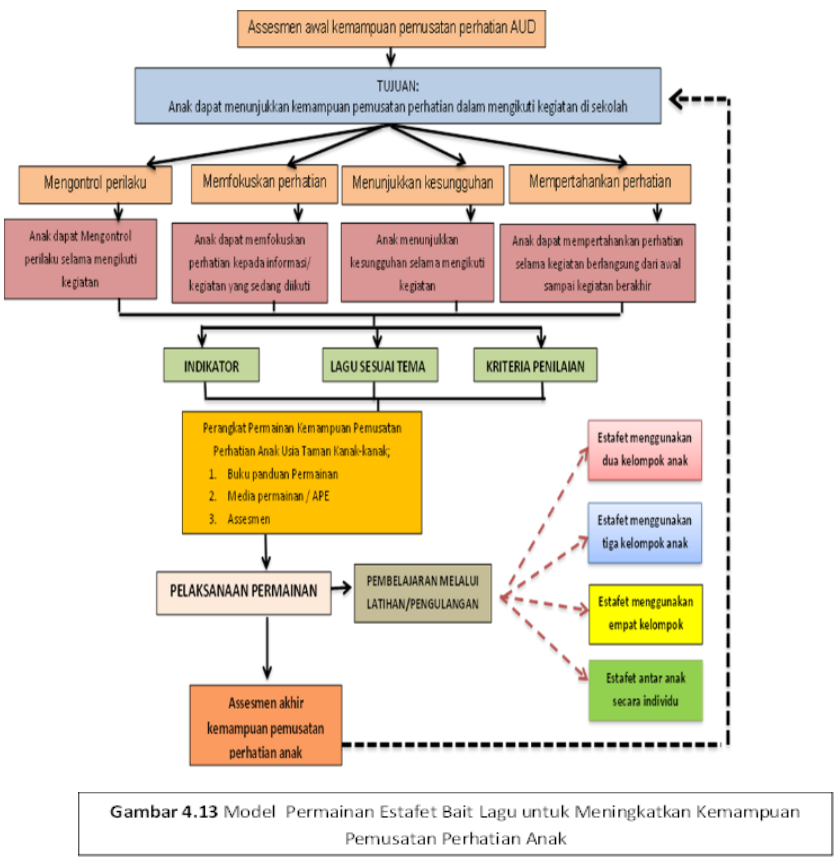

Uji coba I (terbatas) di Kelompok B TK Al Ittihad Bekasi. Data hasil penelitian menunjukkan diperoleh $t_{\text {hitung }}$ sebesar $18,68 t_{\text {tabel }}$ pada uji satu sisi dengan taraf signifikansi 0,05 dengan $\mathrm{n}-1=25$ adalah 1,71 , maka thitung $(11,131)>$ $t_{\text {tabel }}(1,71)$. Kesimpulannya; terlihat peningkatan kemampuan pemusatan perhatian berdasarkan hasil asesmen awal dengan asesmen akhir pada anak Kelompok B3 TK Al-Ittihaad. Hasil uji coba II( uji luas) dilakukan di dua sekolah yaitu TK Al Izzah dan TKIT Iskandar Muda Bekasi. Hasil pengolahan data diperoleh $t_{\text {hitung }}$ sebesar 5,724 $t_{\text {tabel }}$ pada uji satu sisi dengan taraf 
Model Permainan Estafet Bait Lagu... Ismaniar

signifikansi 0,05 dengan $\mathrm{n}-1=24$ adalah 1,71 , maka $t$ hitung $(5,724)>t$ tabel (1,71). Kesimpulannya terjadi peningkatan kemampuan pemusatan perhatian pada anak Kelompok B2 TK Al-Izzah. Hasil perhitungan peningkatan kemampuan pemusatan perhatian anak pada saat asesmen awal dan asesmen akhir di TK Iskandar Muda diperoleh t hitung sebesar 10,319 tabel pada uji satu sisi dengan taraf signifikansi 0,05 dengan $\mathrm{n}-1=18$ adalah 1,73 , maka $\mathrm{t}$ hitung(10,319) > $t$ tabel $(1,73)$. Kesimpulannya; terdapat peningkatan kemampuan pemusatan perhatian pada anak Kelompok B2 TKIT Iskandar Muda.

Berdasarkan hasil penelitian yang telah dikemukakan di atas dapat diketahui bahwa kemampuan pemusatan perhatian pada anak dapat dikembangkan jika cara dan metode yang dilakukan oleh guru memperhatikan karakteristik dan perkembangan anak. Permainan estafet bait lagu merupakan salah solusi yang terbukti dapat dilakukan. Kemampuan pemusatan perhatian tidak dikuasai oleh anak secara tibatiba atau spontan, tetapi perlu dilatihkan kepada mereka secara berulang. Konsep model permainan estafet bait lagu secara teoritik dikembangkan mengacu pada prinsip Law Of Exercise yang dikemukakan Throndike bahwa; suatu kemampuan akan menjadi internal bagi seseorang jika selalu dilatihkan atau diulang. Lebih jauh model permainan estafet bait lagu dirancang dan dikembangkan memperhatikan karakteristik anak usia dini yang suka bermain. David Whitebread (2015) seorang psikolog dari University of Cambridge mengatakan; "Play is often perceived as immature behavior that doesn't achieve anything. But it's essential to their development. They need to learn to persevere, to control attention, to control emotions. Kids learn these things through playing. Salah satu permainan yang disukai anak adalah bermain musik khususnya menyanyi. Hampir semua kegiatan yang dilakukan di TK dimulai atau di akhir dengan nyanyian. Jadi, keputusan pemilihan permainan musik khususnya bernyanyi dalam meningkatkan kemampuan pemusatan perhatian 
anak bertujuan agar latihan yang dilakukan menarik sekaligus menyenangkan bagi anak. Perlu diperhatikan bahwa nyanyian yang digunakan untuk permainan tentunya nyanyian yang sederhana dengan lirik yang tidak terlalu banyak dan sesuai dengan tema di TK.

Model permainan estafet bait lagu merupakan permainan aktif dan suatu bentuk modifikasi dari kegiatan bermain musik. Melalui desain permainan yang dirancang kemampuan pemusatan perhatian secara langsung maupun tidak akan terlatih dan menjadi internal bagi anak. Menurut Baker (2007), seorang profesor di bidang musik dari hasil penelitiannya; Music engages the brain over a period of time, he said, and the process of listening and playing the music could be a way that the brain sharpens its ability to anticipate events and sustain attention. Musik memengaruhi otak selama periode waktu, dan proses mendengarkan dan bermain musik bisa menjadi cara mempertajam kemampuan otak untuk mengantisipasi peristiwa dan mempertahankan perhatian.
Model permainan estafet bait lagu juga memfasilitasi berbagai gaya belajar anak usia dini. Media permainan yang digunakan seperti; penggunaan media poster, bendera aba-aba dan kartu identitas kelompok memfasilitasi anak-anak dengan gaya belajar visual. Penggunaan nyanyian dalam permainan memfasilitasi anak dengan gaya belajar auditori. Sementara penggunaan gerakan-gerakan dalam permainan memfasilitasi anak-anak dengan gaya belajar kinestetik. Secara keseluruhan semua hal tersebut memfasilitasi anak dengan gaya belajar campuran.

Pendidik yang menguasai keterampilan musik yang baik dapat memodifikasi aktifitas musik untuk menghadapi berbagai masalah pada anak usia dini termasuk masalah pemusatan perhatian. Baker (2007), seorang profesor musik mengatakan; Music engages the brain over a period of time, he said, and the process of listening to music could be a way that the brain sharpens its ability to anticipate events and sustain attention.. Semua perasaan positif yang dimiliki akan 
Model Permainan Estafet Bait Lagu... Ismaniar

mendukung setiap orang dalam setiap kegiatan yang diadakan di memusatkan perhatiannya. sekolah.

Selanjutnya pendidik anak usia dini juga harus memiliki pengetahuan dan keterampilan dalam menstimulasi motorik anak, baik motorik halus maupun motorik kasar. Aktivitas bergerak pada anak juga baik bagi perkembangan saraf-saraf otak dan kecerdasan anak. Hasil penelitian Gwen Dewar yang berjudul The Cognitive Benefits of Play: Effects on the Learning Brain (2008-2014) membuktikan bahwa perilaku playfull tampaknya memiliki efek positif pada otak dan kemampuan anak untuk belajar. Bahkan, bermain dapat berfungsi penting sebagai modus untuk belajar. Pengetahuan lainnya yang sangat penting dikuasai pendidik dalam menangani masalah pemusatan perhatian pada anak adalah pengetahuan tentang ilmu kesehatan dan gizi. Anak yang tidak sehat atau sakit-sakitan mudah sekali terganggu konsentrasinya. Seorang pendidik harus memastikan semua anak didiknya dalam keadaan sehat dalam mengikuti setiap kegiatan pembelajaran, sehingga mampu memusatkan perhatiannya dalam

\section{KESIMPULAN DAN SARAN}

\begin{tabular}{l}
\multicolumn{2}{c}{ Kesimpulan dari } \\
pelaksanaan penelitian ini di \\
antaranya;
\end{tabular}

1) Guru belum memiliki metode ataupun cara khusus dalam meningkatkan kemampuan pemusatan perhatian pada anak. Cara-cara yang dilakukan guru terkait penanganan masalah pemusatan perhatian anak selama ini lebih kepada penanggulangan masalah secara incidental.

2) Model permainan estafet bait lagu merupakan model pemusatan perhatian yang didasarkan pada kajian teoritis yang mendalam serta mengalami beberapa tahapan proses uji coba di lapangan. Proses pengembangan Model permainan estafet bait lagu ini memperhatikan karakteristik gaya belajar anak usia dini yang berbeda-beda. Penggunaan Model Permainan Estafet Bait Lagu didukung dengan ada buku panduan permainan, media 
permainan, dan instrument asesmen kemampuan pemusatan perhatian. Validasi dari pakar dan ahli menyatakan model Permainan estafet bait lagu layak digunakan dan cocok untuk anak usia dini.

3) Hasil uji coba model permainan yang dilakukan membuktikan bahwa secara efektif Model Permainan Estafet Bait Lagu dapat meningkatkan kemampuan pemusatan perhatian anak usia dini.

Mengacu pada hasil
penelitian yang diperoleh, maka
dapat dikemukakan saran sebagai
berikut;

1) Pendidik anak usia dini sebaiknya menggunakan model permainan stafet bait lagu dalam meningkatkan kemampuan pemusatan perhatian anak.

2) Pembuat kebijakan diharapkan dapat lebih responsif terhadap berbagai permasalahan yang ada di lapangan. Sehingga berbagai hal yang dapat mengganggu proses pencapaian generasi penerus yang berprestasi dapat ditanggulangi sejak dini.
3) Akademisi khususnya bidang pendidikan anak usia dini, hendaknya semakin memperhatikan pengembangan kemampuan-kemampuan prasyarat dalam memberikan stimulasi perkem-bangan kepada anak. Penguasaan kemampuan prasyarat akan mendukung tercapainya prestasi anak pada setiap aspek pengembangan yang distimulasi.

\section{DAFTAR PUSTAKA}

Abdurrahman, M. (2003). Pendidikan bagi Anak Berkesulitan Belajar. Jakarta: Rineka Cipta.

Alston. (n.d.). Selective Attention: Definition \& Examples. Retrieved January 12, 2014, from https://study.com/academy/less on/selective-attentiondefinition-examplesquiz.html\#lesson

Baker, M. (2007). Music Moves Brain to Pay Attention, Stanford Study Finds. Retrieved December 15, 2015, from https://med.stanford.edu/news/a ll-news/2007/07/music-movesbrain-to-pay-attention-stanfordstudy-finds.html

Berk, L. E. (2006). Child Development (7th ed.). Boston: Pearson Education, Inc. 
Model Permainan Estafet Bait Lagu... Ismaniar

Eggen, P. D., \& Kauchak, D. (2007). Educational Psychology: Windows on Classrooms (5th ed.). New Jersey: Prentice Hall.

Gall, M. D., Borg, W. R., \& Gall, J. P. (2003). Educational Research: An Introduction (7th ed.). Boston: Pearson Education, Inc.

Greenberg, J., \& Baron, R. A. (1995). Behavior in Organizations: Understanding \& Managing the Human Side of Work. New York: Prentice Hall International.

Jamaris, M. (2009). Kesulitan Belajar: Perspektif, Asesmen, dan Penanggulangannya. Jakarta: Yayasan Penamas Murni.

Magill, R. A. (2001). Motor
Learning: Concepts and Applications (6th ed.). New York: McGraw - Hill.

Musfiroh, T. (2008). Cerdas Melalui Bermain. Jakarta: PT Grasindo.

Santrock, J. W. (2002). Life Span Development Perkembangan Masa Hidup (5th ed.). Jakarta: Penerbit Erlangga.

Schunk, D. H. (2012). Learning Theories: An Educational Perspective (6th ed.). Boston: Pearson Education Inc.

Sousa, D. A. (2012). Bagaimana Otak Belajar (4th ed.). Jakarta: Indeks.

Tedjasaputra, M. S. (2001). Bermain, Mainan dan Permainan. Jakarta: Grasindo. 